\title{
From IB2 to IIIB locally advanced cervical cancers: report of a ten-year experience
}

\author{
Sophie Espenel', Max-Adrien Garcia², Jane-Chloé Trone', Elodie Guillaume', Annabelle Harris ${ }^{3}$, \\ Amel Rehailia-Blanchard ${ }^{1}$, Ming Yuan He ${ }^{1}$, Sarra Ouni ${ }^{1}$, Alexis Vallard ${ }^{1}$, Chloé Rancoule ${ }^{1}$, Majed Ben Mrad ${ }^{1}$, \\ Céline Chauleur ${ }^{4}$, Guy De Laroche1 ${ }^{1}$ Jean-Baptiste Guy ${ }^{1}$, Pablo Moreno-Acosta ${ }^{5,6}$ and Nicolas Magné ${ }^{*}$
}

\begin{abstract}
Background: Despite screening campaigns, cervical cancers remain among the most prevalent malignancies and carry significant mortality, especially in developing countries. Most studies report outcomes of patients receiving the usual standard of care. It is possible that these selected patients may not correctly represent patients in a real-world setting, which may be a limitation in interpreting outcomes. This study was undertaken to identify prognostic factors, management strategies and outcomes of locally advanced cervical cancers (LACC) treated in daily clinical practice.
\end{abstract}

Methods: Medical files of all consecutive patients treated with curative intent for LACC in a French Cancer Care Center between 2004 and 2014 were reviewed retrospectively.

Results: Ninety-four patients were identified. Performance status was $\geq 2$ in 10.6\%. Median age at diagnosis was 63.0. Based on the International Federation of Gynecology and Obstetrics classification, tumours were classified as follows: $10.6 \% \mathrm{IB} 2,22.3 \% \mathrm{IIA}, 51.0 \% \mathrm{IIB}, 4.3 \%$ IIIA and $11.7 \%$ IIIB. Pelvic lymph nodes were involved in 34.0\% of cases. Radiotherapy was delivered for all patients. Radiotherapy technique was intensity modulated radiation therapy or volumetric modulated arc therapy in $39.4 \%$ of cases. A concurrent cisplatin chemotherapy was delivered in $68.1 \%$ of patients. Brachytherapy was performed in $77.7 \%$ of cases. The recommended standard care (concurrent chemoradiotherapy with at least five chemotherapy cycles during radiotherapy, followed by brachytherapy) was delivered in $43.6 \%$. The median overall treatment time was 56 days. Complete tumour sterilisation was achieved in $55.2 \%$ of cases. Mean follow-up was 54.3 months. Local recurrence rate was $18.1 \%$. Five-year overall survival was 61.9\% (95\% Confident Interval $(\mathrm{Cl})=52.3-73.2)$ and five-year disease-specific survival was 68.5\% (95\% $\mathrm{Cl}=59.2-79.2$ ). Poor performance status, lymph nodes metastasis and absence of concurrent chemotherapy were identified as poor prognostic factors in multivariate analysis.

Conclusions: Less than 50\% of patients received the standard care. Because LACC patients and disease are heterogeneous, treatment tailoring appears to be common in current clinical practice. However, guidelines for tailoring management are not currently available. More data about real-world settings are required in order to to optimise clinical trials' aims and designs, and make them translatable in daily clinical practice.

Trial registration: retrospectively registered.

Keywords: Locally advanced cervical cancer, Standard care, Daily clinical practice, Radiotherapy, Chemotherapy, Brachytherapy

\footnotetext{
* Correspondence: nicolas.magne@icloire.fr

${ }^{1}$ Radiotherapy Department, Lucien Neuwirth Cancer Institute, 108 bis avenue

Albert Raimond, BP60008, 42271 Saint-Priest-en-Jarez cedex, France

Full list of author information is available at the end of the article
} 


\section{Background}

Despite screening campaigns, cervical cancers remain among the most prevalent malignancies and carry significant mortality, especially in developing countries [1]. Each year, more than 500,000 new cases and 260,000 deaths are reported worldwide. Many patients are diagnosed with locally advanced stages. A concomitant chemoradiotherapy (CCRT), consisting of cisplatin based chemotherapy alongside external beam radiotherapy (EBRT), followed by brachytherapy is considered to be the standard care [2, 3]. A completion surgery may be performed, but the benefits are uncertain [3-5]. Previous literature has reported a 5-year overall survival (OS) ranging from $39.2 \%$ to $80 \%$ in locally advanced cervical cancer (LACC) patients (Table 1) [5-9]. Many prognostic factors were identified- patient characteristics (age [9-11], performance status [11], comorbidities [12, 13]), disease characteristics (stage [6, 9, 11, 14], tumor size [11], lymph nodes metastasis [5, 6, 11], histological type and differentiation $[11,15])$ and treatment characteristics (overall treatment time (OTT) [16], concurrent chemotherapy [6, 15, 17-19] and brachytherapy boost $[2,6,20,21])$. However, 30 to $40 \%$ of patients with similar recognised prognostic factors seem to respond to treatments differently [22]. Biological theories are a current area of research, especially the analysis of the subpopulation of radioresistant tumour cells. The impact of human papillomavirus (HPV) status and variants on prognosis has been identified [22-25], and may lead to the development of antiviral anticancer treatments [26]. Another hypothesis may explain outcomes heterogeneities between publications and daily clinical practice. Most studies assessed prognostic factors and reported outcomes of selected patients receiving the standard care. It is possible that these selected patients may not correctly represent patients in a real-world setting. Therefore, it is of paramount importance to identify prognostic factors in such patients with LACC. This may play a crucial role in tailoring anticancer treatments. The aim of this study was to identify prognostic factors, management strategies and outcomes of LACC treated in daily clinical practice.

\section{Methods}

A retrospective study was conducted at the Lucien Neuwirth Comprehensive Cancer Care Center (SaintPriest-en-Jarez, France). The database was declared to the French Commission of Informatics and Freedom. The study was conducted in compliance with ethical standards and with the 1964 Helsinki Declaration.

\section{Patient population}

Medical records of all consecutive patients treated with curative intent for a LACC between January 2004 and
December 2014 were retrospectively reviewed by a single investigator. Clinical and dosimetric data were collected. LACC was defined as stages IB2 to IIIB according to the 2009 International Federation of Gynecology and Obstetrics (FIGO) classification, regardless of the lymph node status. An ecological index of social deprivation was used to estimate patients' socio-economic status (the French version of the European Deprivation Index [EDI]). Patients were classified into quintiles according to their degree of deprivation, from 1 (least deprived) to 5 (most deprived). Alive patients were contacted in 2017 to obtain the most recent follow-up data.

\section{Work-up and treatment definition Work up}

Pelvic magnetic resonance imaging (MRI) has been available since 2004, and Positron Emission TomographyComputed Tomography (PET-CT) since 2009. For patients included in ERRICC clinical trial (diagnostic performance of 18F- Fluodesoxyglucose -PET and diffusion-weighted MRI in the assessment of stage IB to IIB2 cervical squamous-cell carcinoma response to concomitant radiochemotherapy and brachytherapy, NCT01663753), para-aortic lymph node dissection was performed if no para-aortic involvement was highlighted on the initial PET-CT.

\section{Treatment}

A conventionally fractionated radiation scheme (1.8 to $2 \mathrm{~Gy}$ per fraction) was performed by external beam radiotherapy (EBRT) on the pelvis +/- para-aortic lymph nodes (ei para-aortic lymph nodes involvement according to PET-CT or dissection), to a total dose of at least 45Gy. Pathologic lymph nodes received a higher dose. The clinical target volume (CTV) consisted of the gross tumour volume (GTV), uterus, parametria, vagina at least $2 \mathrm{~cm}$ below the GTV and the pelvic lymph node regions. The planning target volume (PTV) consisted of the CTV with additional 1 to $2 \mathrm{~cm}$ margins. Doses were prescribed and recorded in compliance with the international standard. All treatment plans were optimised according to dose limits for organs at risk. Threedimensional conformal radiotherapy (3D-CRT) was already available before 2004. For 3D-CRT, dose-at-apoint prescription was performed, according to the International Commission on Radiation Units and Measurements (ICRU)-50 and -62. The ICRU point should be located in the central part of the target volume (centroid), and if possible at the point of intersection of the beams. In addition, the dose received in each point of the target volume should be between $95 \%$ and $107 \%$ of the prescribed dose.

Intensity modulated radiotherapy (IMRT) was used since 2008, and volumetric modulated arc therapy 


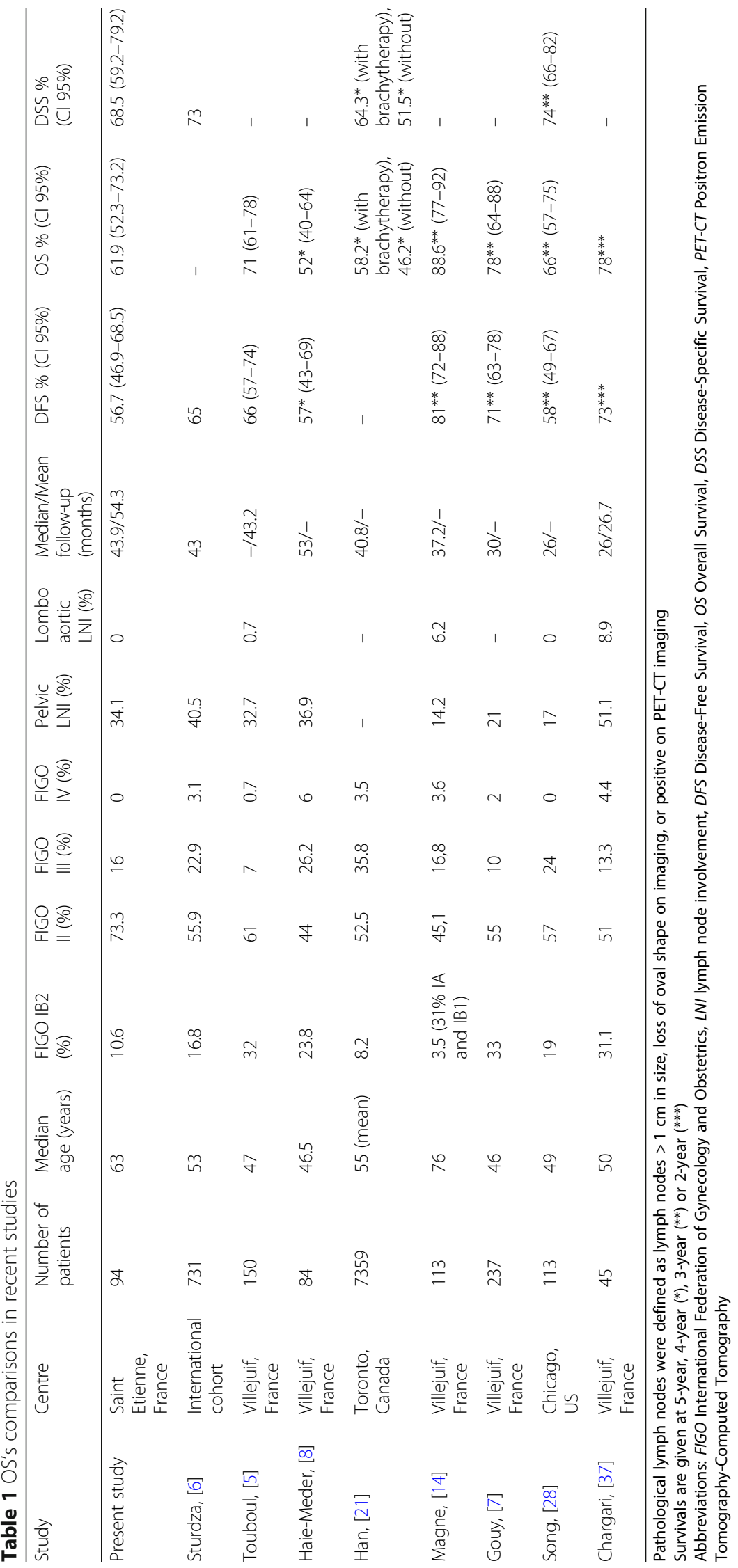


(VMAT) since 2011. For IMRT and VMAT, a dosevolume prescription (corresponding to an isodose) was performed according to the ICRU-83. For each target volume, the median dose (D50\%) and the doses received by $2 \%, 90 \%, 95 \%$ and $98 \%$ of the target volume (respectively D2\%, D90\%, D95\%, D98\%) were reported. Treatment was delivered with a full bladder, and an empty rectum. Cone-beam computed tomography $(\mathrm{CBCT})$ was performed on day one, day two, day three and then twice a week during IMRT or VMAT treatment. Patients underwent concurrent chemotherapy except in cases of contra-indication, incompatible age or refusal. Concurrent chemotherapy consisted of weekly cisplatin $40 \mathrm{mg} / \mathrm{m}^{2}$, or weekly carboplatin area under the curve (AUC) 2 where cisplatin was contra-indicated. This was followed by intracavitary brachytherapy, using a ring and tandem applicator (Nucletron, Sweden from 2004 to 2012; Varian, USA since 2012). Pulsed-dose rates (PDR) with an Iridium-192 stepping source were used. Continuous hourly pulses were delivered $24 \mathrm{~h}$ /day. Treatment planning was based on computed tomographyscan (CT-scan) based dosimetry. Doses were prescribed at point A, according to the American Brachytherapy Society guidelines, and were $\geq 60 G y$. Dose constraints to the bladder and to the rectum were reported according to the ICRU-38 recommendations. No concurrent chemotherapy was delivered during brachytherapy. Finally, colpohysterectomy with bilateral adnexectomy and pelvic lymphadenectomy $(\mathrm{CHL})$ could be performed following a multidisciplinary team decision. Because no recent prospective clinical trial has demonstrated equivalent outcomes with or without completion surgery, CHL was performed for each patient, except in cases of inclusion in ERRICC clinical trial, contra-indication or refusal.

\section{Statistics and results}

Local response to treatment was assessed through histological examination. Efficacy and toxicity of treatment were assessed every three to six months during the subsequent five years, based on physical examination. Biopsies were systematically performed in cases where there was suspicion of tumour recurrence. Local failure was defined as any recurrence in the cervix, parametria, vagina or uterus. Survival rates were calculated from diagnosis to the occurrence of the studied event. The Kaplan Meier method was used to obtain curves of overall survival (OS), disease-specific survival (DSS) and disease-free survival (DFS). 5-year OS, 5-year DSS and 5 -year DFS were given with their 95\% confident interval $(95 \% \mathrm{CI})$. Median values were given with their interquartile range (IQR). All $p$ values were nominal without adjustment for multiple testing. Significance was defined by $p<0.05$. The multivariate analysis was performed using a Cox multivariate analysis based on the significant factors in univariate analysis (log rank test). The multivariate model was refined using the Akaike Information Criterion (AIC). Statistical analyses were processed with R-3.2.2 (R Core Team. R Foundation for Statistical Computing, Vienna, Austria).

\section{Results \\ Patient characteristics (Table 2)}

A total of 94 patients fulfilling the inclusion criteria were identified. Median age at diagnosis was $63.0(\mathrm{IQR}=51.3$ 75.0 ), with $46.8 \%$ over 65 and $39.4 \%$ over 70 . Performance status was 2 for $10.6 \%$ of the patients. Charlson combined age-comorbidity index was 0 for 9 patients $(9.6 \%), 1-2$ for 29 patients (30.9\%), 3-4 for 31 patients $(33.0 \%)$ and $\geq 5$ for 25 patients $(26.6 \%)$. The EDI revealed that 53 patients (56.4\%) appeared to have social deprivation (quartile 4 and 5). Tumours were classified as follows: 10 IB2 stages (10.6\%), 21 IIA stages (22.3\%), 48 IIB stages (51.0\%), 4 IIIA stages $(4.3 \%)$ and 11 IIIB stages (11.7\%). Pelvic lymph nodes were involved in $34.0 \%$ of patients. The two main histologic types were squamous cell carcinoma (76.6\%) and adenocarcinoma (14.9\%). A non squamous cell carcinoma was reported in $32.4 \%$ of patients $>70$ years. The mean pre-radiation haemoglobin level was $12.9 \mathrm{~g} / \mathrm{dL}$.

\section{Work-up and treatment (Table 3)}

The initial work-up included MRI for $92.6 \%$ of patients, cystoscopy for $35.1 \%$ and PET-CT for $33.0 \%$. An optimal CCRT (i.e. concurrent chemoradiotherapy with at least five cycles of chemotherapy followed by a uterovaginal brachytherapy) was performed in 41 patients (43.6\%). IMRT or VMAT were delivered to 37 patients (39.4\%). Regarding patients treated in 2011-2014, IMRT or VMAT were performed in $85.2 \%$ of cases. The median pelvic dose was 46 Gy (IQR = 46-48), with $1.8-2.5$ Gy per fraction. The median number of fractions was 23 $(\mathrm{IQR}=23-25)$. Concurrent chemotherapy was delivered in 81 patients $(86.2 \%)$, mainly with cisplatin $(79.0 \%)$. The mean number of chemotherapy injections was $4(\mathrm{IQR}=$ 3-5). Brachytherapy was delivered to 73 patients (77.7\%), mainly with PDR $(n=72,76.6 \%)$. The mean brachytherapy dose was 25 Gy $(\mathrm{IQR}=24-30)$. The median OTT was 56 days (IQR $=50-63$ ).

Most patients underwent completion surgery $(n=77$, 81.9\%), mainly with CHL ( $n=67,71.3 \%)$. An additional para aortic lymphadenectomy was performed in 30 patients (31.9\%): 23 before the chemoradiotherapy (24.5\%), and 7 simultaneously with the pelvic surgery (7.4\%). Para-aortic lymph node involvement was reported in 4 out of the 7 patients undergoing a post radiation lymphadenectomy.

\section{Survival (Fig. 1)}

With a median follow-up of 43.8 months, the median OS time was 7.6 years. The median DSS time was 
Table 2 Patient characteristics $(n=94)$

\begin{tabular}{|c|c|c|c|c|}
\hline Characteristics & $\begin{array}{l}\text { Whole set of patients } \\
(n=94)\end{array}$ & $\begin{array}{l}\text { Complete CCRT } \\
(n=41)\end{array}$ & $\begin{array}{l}\text { Incomplete CCRT } \\
(n=53)\end{array}$ & $p$-value \\
\hline Age, years, median (IQR) & $63.0(51.3-75.0)$ & $59.1(50.7-73.4)$ & $65.3(54.4-76.0)$ & NS \\
\hline \multicolumn{5}{|l|}{ PS, n (\%) } \\
\hline$P S \leq 1$ & $83(88.3)$ & $24(58.5)$ & $20(37.7)$ & \multirow[t]{3}{*}{$0.03^{\mathrm{a}}$} \\
\hline$P S \geq 2$ & $10(10.6)$ & $16(39.0)$ & $33(62.3)$ & \\
\hline UK & $1(1.1)$ & $1(2.4)$ & $0(0)$ & \\
\hline \multicolumn{5}{|c|}{ Charlson combined age-comorbidity index, $n$ (\%) } \\
\hline 0 & $9(9.6)$ & $4(9.8)$ & $5(9.4)$ & \multirow[t]{4}{*}{ NS } \\
\hline $1-2$ & $29(30.9)$ & $16(39.0)$ & $13(24.5)$ & \\
\hline $3-4$ & $31(33.0)$ & $13(31.7)$ & $18(34.0)$ & \\
\hline$\geq 5$ & $25(26.6)$ & $8(19.5)$ & $17(32.1)$ & \\
\hline \multicolumn{5}{|l|}{ Quintile EDI } \\
\hline 1 & $8(8.5)$ & $4(9.8)$ & $4(7.5)$ & \multirow[t]{6}{*}{ NS } \\
\hline 2 & $15(16.0)$ & $8(19.5)$ & $7(13.2)$ & \\
\hline 3 & $11(11.7)$ & $2(4.9)$ & $9(17.0)$ & \\
\hline 4 & $24(25.5)$ & $14(34.1)$ & $10(18.9)$ & \\
\hline 5 & $29(30.9)$ & $11(26.8)$ & $18(34.0)$ & \\
\hline UK & $7(7.4)$ & $2(4.9)$ & $5(9.4)$ & \\
\hline \multicolumn{5}{|l|}{ Histological type, n (\%) } \\
\hline Squamous cell carcinoma & $72(76.6)$ & $33(80.5)$ & $39(73.6)$ & \multirow[t]{3}{*}{ NS } \\
\hline Adenocarcinoma & $14(14.9)$ & $6(14.6)$ & $8(15.1)$ & \\
\hline Other & $8(8.6)$ & $2(4.9)$ & $6(11.3)$ & \\
\hline \multicolumn{5}{|l|}{ Differentiation grade, n (\%) } \\
\hline High & $24(25.5)$ & $12(29.3)$ & $12(22.6)$ & \multirow[t]{4}{*}{ NS } \\
\hline Moderate & $26(27.7)$ & $12(29.3)$ & $14(26.4)$ & \\
\hline Low & $32(34.0)$ & $12(29.3)$ & $20(37.7)$ & \\
\hline UK & $12(12.8)$ & $5(12.2)$ & $7(13.2)$ & \\
\hline \multicolumn{5}{|l|}{ FIGO Stage, n (\%) } \\
\hline IB2 & $10(10.6)$ & $5(12.2)$ & $5(9.4)$ & \multirow[t]{5}{*}{ NS } \\
\hline$\| \mathrm{A}$ & $21(22.3)$ & $15(36.6)$ & $16(30.2)$ & \\
\hline$\| B$ & $48(51.0)$ & $19(46.3)$ & $29(54.7)$ & \\
\hline IIIA & $4(4.3)$ & $0(0)$ & $4(7.5)$ & \\
\hline IIIB & $11(11.7)$ & $7(17.1)$ & $4(7.5)$ & \\
\hline \multicolumn{5}{|l|}{ Largest MRI tumour diameter, n (\%) } \\
\hline$<4 \mathrm{~cm}$ & $28(29.8)$ & $13(31.7)$ & $15(28.3)$ & \multirow[t]{4}{*}{ NS } \\
\hline 4 to $6 \mathrm{~cm}$ & $27(27.7)$ & $12(29.3)$ & $14(26.4)$ & \\
\hline$>6 \mathrm{~cm}$ & $15(22.3)$ & $4(9.8)$ & $11(20.8)$ & \\
\hline UK & $24(25.5)$ & $10(24.4)$ & $14(26.4)$ & \\
\hline \multicolumn{5}{|c|}{ Lymph node involvement according to initial workup, $\mathrm{n}(\%)$} \\
\hline Pelvic & $32(34.0)$ & $13(31.7)$ & $19(35.8)$ & \multirow[t]{2}{*}{ NS } \\
\hline Para-aortic & $0(0)$ & $0(0)$ & (0) & \\
\hline \multicolumn{5}{|l|}{ Initial workup, n (\%) } \\
\hline Pelvic MRI & $87(92.6)$ & 40 (97.6) & $47(94.0)$ & NS \\
\hline Cystoscopy & $33(35.1)$ & $15(37.5)$ & $18(36.7)$ & NS \\
\hline PET-CT & $31(33.0)$ & $11(28.9)$ & $20(40.0)$ & NS \\
\hline Initial haemoglobin, g/dL, median (IQR) & $12.9(11.9-14.2)$ & $13.1(12.3-14.2)$ & $12.8(11.5-13.9)$ & NS \\
\hline
\end{tabular}

Lymph node involvement is assessed according to the initial workup

Abbreviations: CCRT Concomitant Chemoradiotherapy, IQR Interquartile Range, PS Performance Status, UK Unknown, EDI European Deprivation Index, FIGO International Federation of Gynaecology and Obstetrics, MRI Magnetic Resonance Imaging, PET-CT Positron Emission Tomography-Computed Tomography ${ }^{a}$ Chi square test 
Table 3 Treatment characteristics $(n=94)$

\begin{tabular}{|c|c|c|c|c|}
\hline Characteristics & $\begin{array}{l}\text { Whole set of patients } \\
(n=94)\end{array}$ & $\begin{array}{l}\text { Complete CCRT } \\
(n=41)\end{array}$ & $\begin{array}{l}\text { Incomplete CCRT } \\
(n=53)\end{array}$ & $p$-value \\
\hline Pelvic external radiation therapy, $\mathrm{n}(\%)$ & $94(100)$ & $41(100)$ & $53(100)$ & NS \\
\hline Total dose, median (IQR) & $46(46-48)$ & $46(46-48)$ & $46(46-48)$ & NS \\
\hline Total dose boost, median (IQR) & $55(54-56)$ & $56(54-56)$ & $56(54-57)$ & NS \\
\hline Fractions, median (IQR) & $23(23-25)$ & $23(23-25)$ & $23(23-25)$ & NS \\
\hline Para aortic external radiation therapy, n (\%) & $3(3.2)$ & $1(2.4)$ & $2(3.8)$ & NS \\
\hline \multicolumn{5}{|l|}{ Radiotherapy technique } \\
\hline 3D-CRT, n (\%) & $57(60.6)$ & $26(63.4)$ & $31(58.5)$ & \multirow[t]{2}{*}{ NS } \\
\hline IMRT, VMAT, n (\%) & $37(39.4)$ & 15 (36.6) & $22(41.5)$ & \\
\hline Concurrent chemotherapy, n (\%) & $81(86.2)$ & $41(100)$ & $40(75.5)$ & $<0.01^{\mathrm{a}}$ \\
\hline Number of cycles $\geq 4, n(\%)$ & $69(73.4)$ & $41(100)$ & $28(52.8)$ & $<0.01^{\mathrm{a}}$ \\
\hline Cisplatin, n (\%) & $64(68.1)$ & $34(82.9)$ & $30(56.6)$ & $<0.01^{b}$ \\
\hline Carboplatin, n (\%) & $22(23.4)$ & $11(26.8)$ & $11(20.8)$ & NS \\
\hline Brachytherapy, n (\%) & $73(77.7)$ & $41(100)$ & $32(60.4)$ & $<0.01^{\mathrm{a}}$ \\
\hline PDR, n (\%) & $72(76.6)$ & $40(97.6)$ & $32(60.4)$ & $<0.01^{\mathrm{b}}$ \\
\hline $\mathrm{HDR}, \mathrm{n}(\%)$ & $1(1.1)$ & $1(2.4)$ & $0(0)$ & NS \\
\hline Dose (Gy), median (IQR) & $25(24-30)$ & $26(24-30)$ & $25(24-30)$ & NS \\
\hline OTT (days), median (IQR) & $56(50-63)$ & $55(50-64)$ & $56(53-62)$ & NS \\
\hline Surgery, n (\%) & $77(81.9)$ & $35(85.4)$ & $42(79.2)$ & NS \\
\hline $\mathrm{CHL}, \mathrm{n}(\%)$ & $55(58.5)$ & $27(65.9)$ & $28(52.8)$ & NS \\
\hline $\mathrm{CHL}$ and para aortic lymphadenectomy, n (\%) & $7(7.4)$ & $5(12.2)$ & $2(3.8)$ & NS \\
\hline Other, n (\%) & $15(16)$ & $2(4.9)$ & $11(20.8)$ & $<0.03^{\mathrm{a}}$ \\
\hline Time between brachytherapy and surgery (days), median (IQR) & $42(36-57)$ & $42(34-53)$ & $45(38-57)$ & NS \\
\hline
\end{tabular}

Lymph node involvement is assessed according to the initial workup

Abbreviations: CCRT Concomitant Chemoradiotherapy, IQR Interquartile Range, 3D-CRT 3D Conformal Radiotherapy, IMRT Intensity Modulated Radiotherapy, VMAT Volumetric Modulated Arc Therapy, PDR Pulsed Dose Rate, HDR High Dose Rate, Gy Gray, OTT Overall Treatment Time, CHL Colpohysterectomy with bilateral adnexectomy and pelvic Lymphadenectomy

${ }^{\mathrm{a}}$ Fisher test, ${ }^{\mathrm{b}} \mathrm{Chi}$ square test

12.5 years. The 3-year and 5-year OS were $70.0 \%$ $(95 \% \mathrm{CI}=61.1-82.2)$ and $61.9 \%(95 \% \mathrm{CI}=52.3-73.2)$ respectively. The 3-year and 5-year DSS were $73.8 \%$ $(95 \% \mathrm{CI}=65.1-83.6)$ and $68.5 \% \quad(95 \% \mathrm{CI}=59.2-79.2)$ respectively. The 5 -year DFS was $56.7 \%(95 \% \mathrm{CI}=$ 46.9-68.5). There was a trend toward decrease of OS for patients who had not received the standard care. Completion surgery was associated with a better OS.

\section{Prognostic factors of OS (Table 4)}

Performance status $\leq 1$, uninvolved lymph nodes and concurrent chemotherapy were independent positive prognostic factors of OS in multivariate analysis. For patients with performance status $\leq 1$, or without lymph nodes metastasis, there were not enough events to reach the median OS. Lower bounds of $95 \% \mathrm{CI}$ were respectively 124.0 months and 73.1 months. When concurrent chemotherapy was performed, the median OS was 125 months.

\section{Local control}

Complete tumour sterilisation was achieved in 37 patients (55.2\%). A partial response rate was achieved in 23 patients (34.3\%). No association between tumour sterilisation and FIGO stage or OTT was found. At the end of follow-up, the local recurrence rate was $18.1 \%$. The mean time to local recurrence was 14.2 months $(\mathrm{IQR}=7.2-18.6)$.

\section{Discussion}

This retrospective study highlighted that only a minority (43.6\%) of LACC patients underwent the standard care. This was previously suggested in 15,194 American cervical cancer patients, with only $44.3 \%$ receiving the standard care [2]. Similar data was found in young LACC patients ( $<65$ years), with only $44 \%$ undergoing radio-chemotherapy for at least four concurrent cycles and brachytherapy [27]. Worse, only $25 \%$ completed the treatment in less than 56 days. In the present study, the OTT was longer than 56 days for half of patients. 


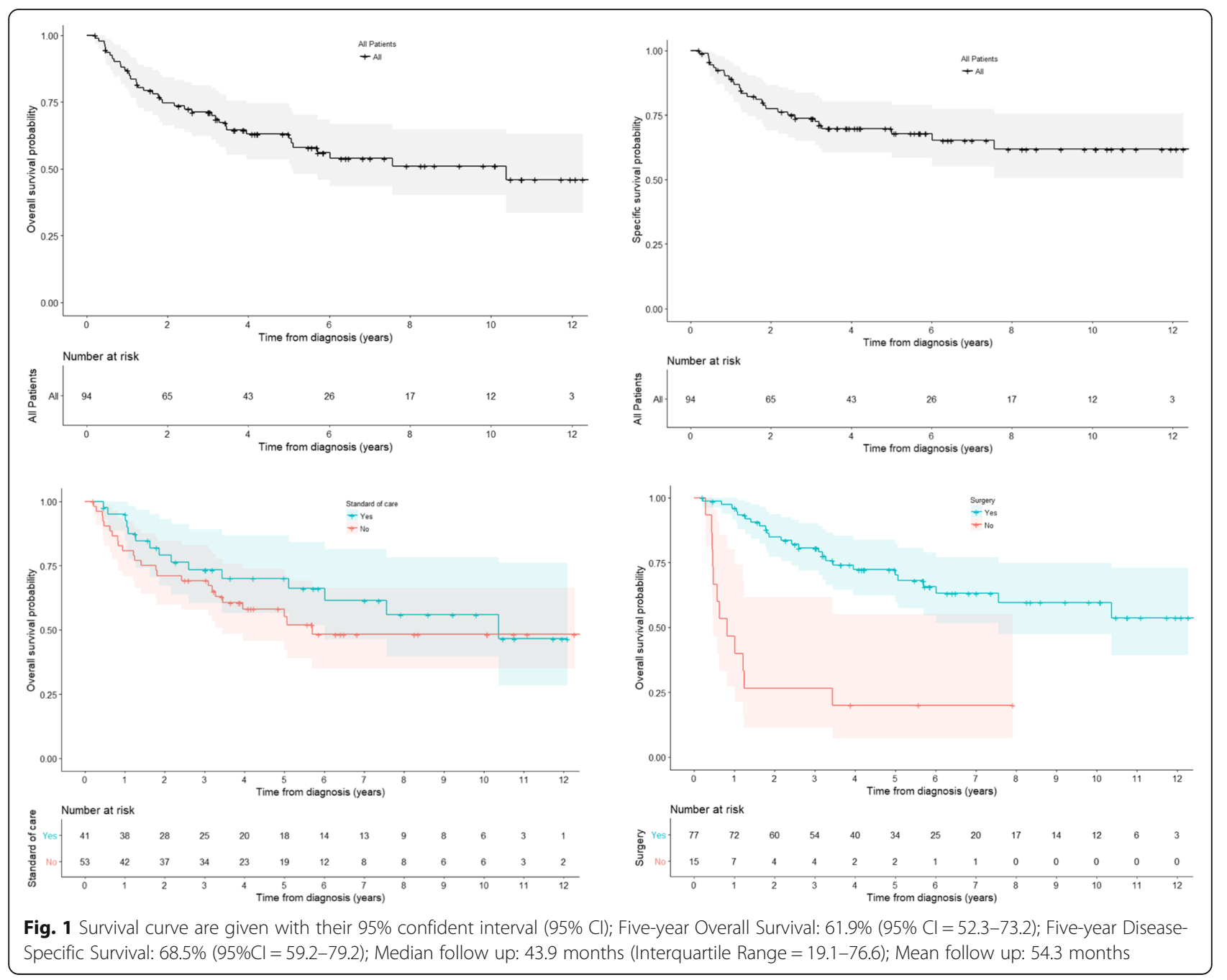

Although an OTT $\leq 56$ days improves the pelvic control, it does not seem to impact anymore on OS and DSS since concurrent chemoradiation was developed [28, 29].

American studies had shown that high volume centres, higher density of radiation oncologists, academic centres, comprehensive community cancer centres, private insurance, higher income, and younger age were all associated with an increased likelihood of receiving standard care, whereas Black patients were less likely to receive standard care [2, 11, 27]. Adherence to standard care in high volume centres with high density of radiation oncologists probably reflects that access to the multidisciplinary resources needed (gynaecological oncologists, radiation oncologists expert in EBRT and brachytherapy, anaesthetists, operating suites, other radiation facilities equipped with a brachytherapy) and coordination are challenging. Territorial or socio-economic inequalities could not be accurately studied in this mono-centric study. Data from other European cancer care centres is needed.
We found that there was a trend towards decrease of adherence to standard care with age. However, the main characteristic associated with adherence to standard care was the performance status. This data suggests that deviation from the recommended treatment could result from treatment tailoring. Incidentally, overall survival was not significantly higher for patients receiving standard care than for others. Conversely, overall survival was significantly lower for patients who did not undergo a completion surgery, probably reflecting their frailty (contraindication to surgery) more than surgery benefit.

The fact that many publications only included patients receiving standard care widely restricts the external validity of researches $[5,8,28]$. This point raises serious concerns on outcome interpretation since it was demonstrated that deviations from standard care in multi-centre phase III clinical trials was associated with decreased survival $[2,28,29]$. Moore et al. analysed the treatment received by 1490 patients with a LACC, 
Table 4 Prognostic factors of overall survival: univariate and multivariate analysis

\begin{tabular}{|c|c|c|c|c|c|c|c|}
\hline Variables & $\begin{array}{l}\text { Tested vs } \\
\text { adverse criteria }\end{array}$ & $\begin{array}{l}\text { Adverse criterion present } \\
\text { median overall survival } \\
\text { (months) }\end{array}$ & $\begin{array}{l}\text { Adverse criterion absent } \\
\text { median overall survival } \\
\text { (months) }\end{array}$ & $\begin{array}{l}p \text {-value } \\
\text { (Log rank test) }\end{array}$ & $\begin{array}{l}\text { Adjusted } \\
\text { Hazard } \\
\text { Ratio }\end{array}$ & $95 \% \mathrm{Cl}$ & $\begin{array}{l}p \text {-value } \\
\text { (Cox model) }\end{array}$ \\
\hline Age (years) & $\geq 65(v s<65)$ & 73.1 & 90.9 & $p=0.361$ & - & - & - \\
\hline PS & $P S>1(v s \leq 1)$ & 48.6 & $>124.0^{*}$ & $p<0.001$ & 2.86 & $1.41-5.79$ & $p=0.003$ \\
\hline Histology & No SCC (vs SCC) & 61.2 & 124.9 & $p=0.262$ & - & - & - \\
\hline Differentiation & $\begin{array}{l}\text { Moderate or low } \\
\text { (vs high) }\end{array}$ & 73.1 & 90.9 & $p=0.899$ & - & - & - \\
\hline FIGO stage & III (vs IB2 and II) & 37.4 & 90.9 & $p=0.336$ & - & - & - \\
\hline $\begin{array}{l}\text { Pelvic lymph } \\
\text { nodes involvement }\end{array}$ & Yes (vs no) & 41.1 & $>73.1^{*}$ & $p=0.003$ & 1.95 & $1.03-3.69$ & $p=0.040$ \\
\hline MRI tumor size $(\mathrm{mm})$ & $\geq 50($ vs $<50)$ & 32 & $>124.9^{*}$ & $p=0.006$ & - & - & - \\
\hline Hemoglobin (g/dL) & $<11(\mathrm{vs} \geq 11)$ & 13.0 & $>63.0^{*}$ & $p=0.013$ & - & - & - \\
\hline Radiotherapy & $\begin{array}{l}\text { 3D-CRT (vs IMRT } \\
\text { or VMAT) }\end{array}$ & 73 & $>61.0^{*}$ & $p=0.500$ & & & \\
\hline $\begin{array}{l}\text { Concurrent } \\
\text { chemotherapy }\end{array}$ & No (vs yes) & 17 & 125.0 & $p=0.014$ & 2.33 & $1.06-5.16$ & $p=0.035$ \\
\hline Brachytherapy & No (vs yes) & 37.4 & 124.9 & $p=0.428$ & - & - & - \\
\hline OTा (days) & $>55(\mathrm{vs} \leq 55)$ & 62.9 & 124.9 & $p=0.428$ & - & - & - \\
\hline $\begin{array}{l}\text { Complete tumor } \\
\text { sterilization }\end{array}$ & No (vs yes) & 90.9 & $>69.1^{*}$ & $p=0.256$ & - & - & - \\
\hline
\end{tabular}

Abbreviations: Cl Confident Interval, SCC Squamous Cell Carcinoma, PS Performance Status FIGO International Federation of Gynecology and Obstetrics, MRI Magnetic Resonance Imaging; 3DCRT 3D Conformal Radiotherapy, IMRT Intensity Modulated Radiotherapy, VMAT Volumetric Modulated Arc Therapy, OTT Overall Treatment Time

Legend: Univariate analysis was performed using Log-rank test, multivariate analysis using Cox model

$*=95 \% \mathrm{Cl}$ lower bound (not enough event to reach median overall survival)

treated in Gynecologic Oncology Group (GOG) phase I-III trials [11]. Even in well-conducted clinical trials, the treatment significantly varied with age. Brachytherapy was reported to be performed less often in elderly patients, although it has been suggested it is safe among the oldest patients $[11,14,21]$. In the present study, brachytherapy was delivered in only three quarters of patients. Previous studies assessing real-life practice have shown similar data (55\% to $88 \%$ in North America) $[21,30]$. Yet, OS and PFS were proven to be increased by brachytherapy and survival rates of patients receiving brachytherapy were higher than patients treated with external boost [2, 20,21]. Guidelines recommend delivering high dose rate (HDR) brachytherapy, planned with CT-scan or MRI [29, 31]. However, as it has been suggested that CT-scanning can overestimate the tumour width compared with MRI, MRI-based brachytherapy might allow a better dose-volume adaptation and dose escalation [32]. Consequently, MRIbased brachytherapy could give better local control, and fewer side effects [31-37]. It therefore seems to be an interesting option, even in poor condition patients, for which brachytherapy tolerance is sometimes questioned.

Patients $>65$ years old represented less than $1 \%$ of the overall population in randomised clinical trials assessing concurrent cisplatin-based chemotherapy [17]. This result suggests that the standard care was not properly assessed in the geriatric population. The absence of a consensus concerning elderly-population-adapted treatments makes any therapeutic decision difficult. An onco-geriatric evaluation should therefore be performed before any treatment, in order to optimise the therapeutic strategy. In older people, comorbidities associated with cancer are known to induce poorer prognoses and lower adherence to standard care $[12,13]$. In the present study, the Charlson combined age-comorbidity index revealed severe comorbidities in $26.6 \%$ of patients, at least partly explaining why a concurrent chemotherapy was only delivered in $86.0 \%$ of patients, with $68.1 \%$ receiving cisplatin. The RetroEMBRACE international cohort study reported that $76.5 \%$ of cervical cancer patients were prescribed chemotherapy between 1998 and 2012 [6]. The American National Cancer Database reported very similar results, with $74.7 \%$ in 2004-2012 [2]. However, chemotherapy is known to impact the OS. The Cochrane review reported a $6 \%$ improvement in 5 -year OS with chemoradiotherapy, an $8 \%$ improvement in 5year progression free survival (PFS), and a 9\% improvement in 5-year local control [17]. The absolute benefit in OS and PFS was estimated at $12 \%(95 \% \mathrm{CI}=8-16)$ and $16 \%(95 \% \mathrm{CI}=13-19)$ respectively [18].

Age and comorbidities did not appear to impact EBRT treatment. In the present study, EBRT was always delivered, with a median pelvic dose of 46 Gy (IQR $=46-48$ ). 
Technically advanced EBRT was used, often with IMRT or VMAT. IMRT is currently the recommended radiotherapy technique to treat LACC. It has been shown to preserve critical organs better than 3D-CRT, particularly bone marrow and bowels $[38,39]$. It may enable the intensification of radiosensitisation or the addition of adjuvant treatment, particularly in cases with poor prognostic factors. One of the most important poor prognostic factors is lymph node involvement, which was reported in $34.1 \%$ of participants in this study. It was statistically associated with lower OS, as described in the GOG phase I-III trials analysis [11]. When stratified by FIGO stage, the hazard ratio associated with positive lymph nodes is estimated at 3.3 (95\% CI $2.8-$ 4.0) in cervical cancer patients [9]. The presence, in addition to the level, of nodal spread were described as prognostic factors of OS [5]. This strong association between lymph node involvement and OS could therefore suggest identifying LACC with and without lymph nodes involvement, and to consider different therapeutic strategies. Many clinical trials are assessing treatment intensification, with immunotherapy, target therapy or antiviral treatment addition (NCT03298893, NCT02 705612, NCT02501278, NCT01217177, NCT00023660, NCT00369122, etc), concomitant chemotherapy intensification (NCT01561586, NCT00292955, NCT00548821, etc), or adjuvant treatment (NCT02036164, NCT02 853604 , etc). Other clinical trials are assessing new treatment strategies, such as alternative medical treatments or improvements in coordination of care. The European Organisation for Research and Treatment of Cancer (EORTC) is comparing the effectiveness of chemotherapy followed by surgery, versus CCRT in patients with stage IB or II cervical cancer (EORTC 55994, NCT00 039338). This strategy could be an interesting alternative to CCRT, which seems difficult to observe in a realworld setting.

\section{Conclusions}

OS and OSS were previously often estimated in patients receiving the standard care. However, previous American real-life studies revealed that less than $50 \%$ of the patients underwent it. The present study confirms this result in a French Cancer Care Centre, reflecting how often heterogeneous patient and disease characteristics required treatment adaptation, and how often physician communication and coordination can result in difficulties in providing multiple components of cervical cancer treatment. Selected patients in clinical trials do not seem to accurately reflect the characteristics of the real-world population. The standard care of frail patients is still to be defined, but involvement of oncogeriatrics may already be enhancing elderly patients' outcomes. For fit patients with poor prognostic factors, such as lymph node involvement, escalation therapy could be assessed in clinical trials. More data about treatment and outcomes in a real-world setting is required in order to optimise clinical trials and daily clinical practice.

\section{Abbreviations \\ 3D-CRT: 3D-Conformal radiotherapy; AIC: Akaike Information Criterion; AUC: Area under the curve; CBCT: Cone-beam computed tomographic; CCRT: Concomitant chemoradiotherapy; CHL: Colpohysterectomy with bilateral adnexectomy and pelvic Lymphadenectomy; Cl: Confident interval; CT-scan: Computed Tomography-scan; CTV: Clinical target volume; DFS: Disease-free survival; DSS: Disease-specific survival; EBRT: External beam radiation therapy; EDI: European Deprivation Index; EORTC: European Organisation for Research and Treatment of Cancer; FIGO: International Federation of Gynecology and Obstetrics; GOG: Gynecologic Oncology Group; GTV: Gross Tumor Volume; Gy: Gray; HDR: High dose rate; HPV: Human papillomavirus; ICRU: International Commission on Radiation Units and measurements; IMRT: Intensity modulated radiotherapy; IQR: Interquartile range; LACC: Locally advanced cervical cancer; MRI: Magnetic resonance imaging; OS: Overall survival; OTT: Overall treatment time; PDR: Pulsed-dose rate; PET-CT: Positron Emission Tomography-Computed Tomography; PFS: Progression free survival; PTV: Planning target volume; VMAT: Volumetric modulated arc therapy}

\begin{abstract}
Acknowledgements
Not applicable.

Funding

None.

Availability of data and materials

The datasets analysed during this study are available from the corresponding author on reasonable request.

Authors' contributions

SE, NM, CC, JCT, and CR conceived the study and participated in its design and coordination. SE, EG, AV, MBM, SO and MYH performed the data acquisition. SE, MAG, and RBA interpreted the data. SE, MAG and NM drafted the manuscript. $C C, G D L, P M A, J B G, N M$ and $A H$ reviewed the manuscript. All authors read and approved the final manuscript.
\end{abstract}

Ethics approval and consent to participate

The database has been declared to the French Commission of Informatics and Freedom. The study was conducted in compliance with the Helsinki Declaration.

\section{Consent for publication}

Not applicable.

\section{Competing interests}

The authors declare that they have no competing interests.

\section{Publisher's Note}

Springer Nature remains neutral with regard to jurisdictional claims in published maps and institutional affiliations.

\footnotetext{
Author details

${ }^{1}$ Radiotherapy Department, Lucien Neuwirth Cancer Institute, 108 bis avenue Albert Raimond, BP60008, 42271 Saint-Priest-en-Jarez cedex, France. ${ }^{2}$ Public Health Department, Lucien Neuwirth Cancer Institute, 108 bis avenue Albert Raimond, BP60008, 42271 Saint-Priest-en-Jarez cedex, France. ${ }^{3}$ Chelsea and Westminster Hospital, 369 Fulham Road, London SW10 9NH, UK. ${ }^{4}$ Obstetrics and Gynecology Department, Saint Etienne University Hospital Medical Center, avenue Albert Raimond, BP60008, 42271 Saint-Priest-en-Jarez cedex, France. ${ }^{5}$ Research Group in Radiobiology Clinical, Molecular and Cellular, National Cancer Institute, Bogotá, Colombia. ${ }^{6}$ Research Group in Cancer Biology, National Cancer Institute, Bogotá, Colombia.
} 
Received: 3 August 2017 Accepted: 24 January 2018 Published online: 02 February 2018

\section{References}

1. Ferlay J, Soerjomataram I, Dikshit R, Eser S, Mathers C, Rebelo M, et al. Cancer incidence and mortality worldwide: sources, methods and major patterns in GLOBOCAN 2012. Int J Cancer. 2015;136:359-86.

2. Robin TP, Amini A, Schefter TE, Behbakht K, Fisher CM. Disparities in standard of care treatment and associated survival decrement in patients with locally advanced cervical cancer. Gynecol Oncol. 2016;143: 319-25.

3. National Comprehensive Cancer Network (US) NCCN Clinical Practice Guidelines in Oncology. Cervical cancer, version 1.2017. Fort Washington, PA: National Comprehensive Cancer Network; 2017.

4. Keys HM, Bundy BN, Stehman FB, Okagaki T, Gallup DG, Burnett AF, et al. Radiation therapy with and without extrafascial hysterectomy for bulky stage IB cervical carcinoma: a randomized trial of the gynecologic oncology group. Gynecol Oncol. 2003;89:343-53.

5. Touboul C, Uzan C, Mauguen A, Gouy S, Rey A, Pautier P, et al. Survival and prognostic factors after completion surgery in patients undergoing initial chemoradiation therapy for locally advanced cervical cancer. Gynécologie Obstétrique \& Fertilité. 2011;39:274-80.

6. Sturdza A, Pötter R, Fokdal LU, Haie-Meder C, Tan LT, Mazeron R, et al. Image guided brachytherapy in locally advanced cervical cancer: improved pelvic control and survival in RetroEMBRACE, a multicenter cohort study. Radiother Oncol. 2016;120:428-33.

7. Gouy S, Morice P, Narducci F, Uzan C, Martinez A, Rey A, et al. Prospective multicenter study evaluating the survival of patients with locally advanced cervical cancer undergoing laparoscopic Para-aortic Lymphadenectomy before Chemoradiotherapy in the era of positron emission tomography imaging. J Clin Oncol. 2013;31:3026-33.

8. Haie-Meder C, Chargari C, Rey A, Dumas I, Morice P, Magné N. MRIbased low dose-rate brachytherapy experience in locally advanced cervical cancer patients initially treated by concomitant chemoradiotherapy. Radiother Oncol. 2010;96:161-5.

9. Quinn MA, Benedet JL, Odicino F, Maisonneuve P, Beller U, Creasman WT, et al. Carcinoma of the cervix uteri. FIGO 26th annual report on the results of treatment in gynecological cancer. Int J Gynaecol Obstet. 2006;95(Suppl 1):S43-103.

10. Wright JD, Gibb RK, Geevarghese S, Powell MA, Herzog TJ, Mutch DG, et al. Cervical carcinoma in the elderly: an analysis of patterns of care and outcome. Cancer. 2005;103:85-91.

11. Moore KN, Java JJ, Slaughter KN, Rose PG, Lanciano R, DiSilvestro PA, et al. Is age a prognostic biomarker for survival among women with locally advanced cervical cancer treated with chemoradiation? An NRG oncology/ gynecologic oncology group ancillary data analysis. Gynecol Oncol. 2016;143: 294-301.

12. Piccirillo JF, Tierney RM, Costas I, Grove L, Spitznagel EL. Prognostic importance of comorbidity in a hospital-based cancer registry. JAMA. 2004;291:2441-7.

13. Yates JW. Comorbidity considerations in geriatric oncology research. CA Cancer J Clin. 2001;51:329-36.

14. Magné N, Mancy NC, Chajon E, Duvillard P, Pautier P, Castaigne D, et al. Patterns of care and outcome in elderly cervical cancer patients: a special focus on brachytherapy. Radiother Oncol. 2009:91:197-201.

15. Keys HM, Bundy BN, Stehman FB, Muderspach LI, Chafe WE, Suggs CL, et al. Cisplatin, radiation, and adjuvant hysterectomy compared with radiation and adjuvant hysterectomy for bulky stage IB cervical carcinoma. N Engl J Med. 1999;340:1154-61.

16. Perez CA, Grigsby PW, Castro-Vita H, Lockett MA. Carcinoma of the uterine cervix. I. Impact of prolongation of overall treatment time and timing of brachytherapy on outcome of radiation therapy. Int J Radiat Oncol Biol Phys. 1995:32:1275-88.

17. Chemoradiotherapy for Cervical Cancer Meta-analysis Collaboration (CCCMAC). Reducing uncertainties about the effects of chemoradiotherapy for cervical cancer: individual patient data meta-analysis. Cochrane Database Syst Rev. 2010:CD008285.

18. Green JA, Kirwan JM, Tierney JF, Symonds P, Fresco L, Collingwood M, et al. Survival and recurrence after concomitant chemotherapy and radiotherapy for cancer of the uterine cervix: a systematic review and meta-analysis. Lancet. 2001;358:781-6.
19. Rose PG, Bundy BN, Watkins EB, Thigpen JT, Deppe G, Maiman MA, et al. Concurrent cisplatin-based radiotherapy and chemotherapy for locally advanced cervical cancer. N Engl J Med. 1999;340:1144-53.

20. Karlsson J, Dreifaldt A-C, Mordhorst LB, Sorbe B. Differences in outcome for cervical cancer patients treated with or without brachytherapy. Brachytherapy. 2016;16:133-40.

21. Han K, Milosevic M, Fyles A, Pintilie M, Viswanathan AN. Trends in the utilization of brachytherapy in cervical cancer in the United States. Int J Radiat Oncol Biol Phys. 2013;87:111-9.

22. Moreno-Acosta P, Vallard A, Molano M, Huertas A, Gamboa Ó, Cotes M, et al. HPV-16 variants' impact on uterine cervical cancer response to radiotherapy: a descriptive pilot study. Cancer Radiother. 2017;21:104-8.

23. Magné N, Chargari C, Deutsch E, Castadot P, Ghalibafian M, Bourhis J, et al. Molecular profiling of uterine cervix carcinoma: an overview with a special focus on rationally designed target-based anticancer agents. Cancer Metastasis Rev. 2008;27:737-50.

24. Moreno-Acosta P, Gamboa O, Sanchez de Gomez M, Cendales R, Diaz $\mathrm{GD}$, Romero A, et al. IGF1R gene expression as a predictive marker of response to ionizing radiation for patients with locally advanced HPV16 positive cervical cancer. Anticancer Res. 2012;32:4319-25.

25. Moreno-Acosta P, Carrillo S, Gamboa O, Romero-Rojas A, Acosta J, Molano $\mathrm{M}$, et al. Novel predictive biomarkers for cervical cancer prognosis. Mol Clin Oncol. 2016;5:792-6.

26. Deutsch E, Haie-Meder C, Bayar MA, Mondini M, Laporte M, Mazeron R, et al. Phase I trial evaluating the antiviral agent Cidofovir in combination with chemoradiation in cervical cancer patients. Oncotarget. 2016;7:25549-57.

27. Smith GL, Jiang J, Giordano SH, Meyer LA, Eifel PJ. Trends in the quality of treatment for patients with intact cervical cancer in the United States, 1999 through 2011. Int J Radiat Oncol Biol Phys. 2015;92:260-7.

28. Song S, Rudra S, Hasselle MD, Dorn PL, Mell LK, Mundt AJ, et al. The effect of treatment time in locally advanced cervical cancer in the era of concurrent chemoradiotherapy. Cancer. 2013;119:325-31.

29. Viswanathan AN, Beriwal S, De Los Santos JF, Demanes DJ, Gaffney D, Hansen J, et al. American Brachytherapy society consensus guidelines for locally advanced carcinoma of the cervix. Part II: high-dose-rate brachytherapy. Brachytherapy. 2012;11:47-52.

30. Eifel PJ, Ho A, Khalid N, Erickson B, Owen J. Patterns of radiation therapy practice for patients treated for intact cervical cancer in 2005 to 2007: a quality research in radiation oncology study. Int J Radiat Oncol Biol Phys. 2014:89:249-56.

31. Viswanathan AN, Dimopoulos J, Kirisits C, Berger D, Pötter R. Computed tomography versus magnetic resonance imaging-based contouring in cervical cancer brachytherapy: results of a prospective trial and preliminary guidelines for standardized contours. Int J Radiat Oncol Biol Phys. 2007;68: 491-8.

32. Pötter R, Dimopoulos J, Georg P, Lang S, Waldhäusl C, Wachter-Gerstner N, et al. Clinical impact of MRI assisted dose volume adaptation and dose escalation in brachytherapy of locally advanced cervix cancer. Radiother Oncol. 2007:83:148-55.

33. Haie-Meder C, Pötter R, Van Limbergen E, Briot E, De Brabandere M, Dimopoulos J, et al. Recommendations from Gynaecological (GYN) GECESTRO working group (I): concepts and terms in 3D image based 3D treatment planning in cervix cancer brachytherapy with emphasis on MRI assessment of GTV and CTV. Radiother Oncol. 2005;74:235-45.

34. Pötter R, Haie-Meder C, Van Limbergen E, Barillot I, De Brabandere M, Dimopoulos J, et al. Recommendations from gynaecological (GYN) GEC ESTRO working group (II): concepts and terms in 3D image-based treatment planning in cervix cancer brachytherapy-3D dose volume parameters and aspects of 3D image-based anatomy, radiation physics, radiobiology. Radiother Oncol. 2006;78:67-77.

35. Tanderup K, Nielsen SK, Nyvang G-B, Pedersen EM, Røhl L, Aagaard T, et al. From point a to the sculpted pear: MR image guidance significantly improves tumour dose and sparing of organs at risk in brachytherapy of cervical cancer. Radiother Oncol. 2010;94:173-80.

36. Haie-Meder C, Thomas L, Barillot I, Pommier P, Nickers P. Image-guided adaptive brachytherapy in the treatment of patients with cervix cancer. Cancer Radiother. 2013;17:98-105.

37. Chargari C, Magné N, Dumas I, Messai T, Vicenzi L, Gillion N, et al. Physics contributions and clinical outcome with 3D-MRI-based pulsed-dose-rate intracavitary brachytherapy in cervical cancer patients. Int J Radiat Oncol Biol Phys. 2009;74:133-9. 
38. Brixey CJ, Roeske JC, Lujan AE, Yamada SD, Rotmensch J, Mundt AJ. Impact of intensity-modulated radiotherapy on acute hematologic toxicity in women with gynecologic malignancies. Int J Radiat Oncol Biol Phys. 2002;54:1388-96.

39. Guy J-B, Falk AT, Auberdiac P, Cartier L, Vallard A, Ollier E, et al.

Dosimetric study of volumetric arc modulation with RapidArc and intensity-modulated radiotherapy in patients with cervical cancer and comparison with 3-dimensional conformal technique for definitive radiotherapy in patients with cervical cancer. Med Dosim. 2016;41:9-14.

Submit your next manuscript to BioMed Central and we will help you at every step:

- We accept pre-submission inquiries

- Our selector tool helps you to find the most relevant journal

- We provide round the clock customer support

- Convenient online submission

- Thorough peer review

- Inclusion in PubMed and all major indexing services

- Maximum visibility for your research

Submit your manuscript at www.biomedcentral.com/submit 